\title{
Socio-economic factors associated with a healthy diet: results from the E3N study
}

\author{
Aurélie Affret ${ }^{1,2}$, Gianluca Severi ${ }^{1,2,3,4}$, Courtney Dow ${ }^{1,2}$, Grégoire Rey ${ }^{5}$, \\ Cyrille Delpierre ${ }^{6}$, Marie-Christine Boutron-Ruault ${ }^{1,2}$, Françoise Clavel-Chapelon ${ }^{1,2}$ \\ and Guy Fagherazzi ${ }^{1,2, *}$ \\ 'Inserm U1018, Center for Research in Epidemiology and Population Health (CESP), Team 9, Nutrition, Hormones and \\ Women's Health, Gustave Roussy Institute, 114 rue Edouard Vaillant, 94805 Villejuif Cedex, France: ${ }^{2}$ Paris-South \\ University, Villejuif, France: ${ }^{3}$ Human Genetics Foundation (HuGeF), Torino, Italy: ${ }^{4}$ Cancer Epidemiology Centre, Cancer \\ Council Victoria and The University of Melbourne, Melbourne, Australia: ${ }^{5}$ Inserm, CépiDc, Le Kremlin-Bicêtre, France: \\ Onserm U1027, Faculty of Medicine, Toulouse, France
}

Submitted 27 July 2016: Final revision received 16 January 2017: Accepted 23 January 2017: First published online 13 March 2017

\begin{abstract}
Objective: To identify individual and contextual socio-economic factors associated with a healthy diet.

Design: Dietary data from a large cohort study were used to derive two mutually exclusive dietary patterns through a latent class analysis. Associations between dietary patterns and socio-economic factors were studied with logistic regression. Setting: E3N, a French prospective cohort study composed of women recruited from a national health insurance plan covering people working in the national education system.

Subjects: E3N participants ( $n$ 73031) with dietary and socio-economic data available.

Results: The 'Healthy' pattern was characterized by a large consumption of fruits and vegetables and the 'Less Healthy' pattern by a large consumption of pizza and processed meat. When all socio-economic factors were analysed together, all of the individual factors considered were associated with a healthy diet (e.g. women with three or more children were less likely to follow a healthy diet $v$. women with no children, OR $(95 \% \mathrm{CI}): 0 \cdot 70(0 \cdot 66,0.75))$ while the contextual factors associated with a healthy diet included the size of the agglomeration of residence and the area of birth and residence (e.g. women living in the West of France were less likely to follow a healthy diet $v$. those living in the South of France: $0.78(0.72,0.83)$ ).

Conclusions: We demonstrated that individual and contextual factors are both associated with diet. Rather than focusing only on individual factors, we recommend future studies or public health and nutritional strategies on diet to consider both types of factors.
\end{abstract}

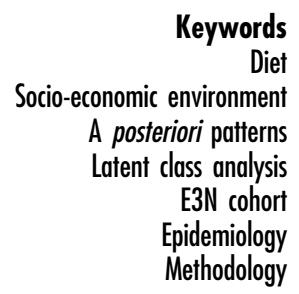

Foods and nutrients are not consumed in isolation. They form a network of complex interactions that can be best considered with a dietary pattern approach ${ }^{(1,2)}$. There is growing evidence of moderate to strong associations between healthy dietary patterns and decreased risk of obesity and chronic diseases such as CVD, hypertension, type 2 diabetes and some cancers ${ }^{(3,4)}$. In most studies, dietary patterns are derived from principal component analysis or factor analysis. These methods reduce the number of dimensions by determining factors that are linear combinations of dietary variables ${ }^{(2)}$. However, one major limitation is that estimated dietary patterns are not mutually exclusive; one individual may simultaneously have high adherence scores to several patterns. Although this could be the result of a multifactorial reality, it makes interpretation difficult.

Previous studies have demonstrated that individual and contextual socio-economic factors are strong determinants of dietary habits ${ }^{(5-9)}$, with lower socio-economic groups being less likely to purchase and consume healthy products. Among contextual factors, the area of residence has been shown to be of importance, particularly in France where an interaction between the level of education and the area of residence (South of France $v$. the other regions) has been previously suggested ${ }^{(10,11)}$. Furthermore, overall mortality and cause-specific mortality are higher in groups of 
lower socio-economic status at the individual ${ }^{(12,13)}$ and residential area level ${ }^{(14)}$. Lower socio-economic groups also have poorer health consciousness and are more frequently obese $^{(15)}$ or diabetic ${ }^{(16,17)}$. In this context and despite the fact that experts agree that the socio-economic environment is complex and multifactorial, its influence has generally been studied by considering a single specific and conventional socio-economic factor ${ }^{(18)}$ such as education ${ }^{(19)}$ or income $\operatorname{tax}^{(11)}$. Nevertheless, considering various socio-economic factors together to capture the multidimensional nature of socio-economic status, and not assuming that different socio-economic measures are interchangeable, has been reported to be of importance ${ }^{(18,20)}$. Socio-economic variables are each operationally distinct and may influence health behaviours by conceptually different processes ${ }^{(20)}$. It is therefore of interest to study the influence of the socio-economic environment by simultaneously considering different factors. The socio-economic position of an individual is likely to be the result of all existing interactions between individual and contextual socio-economic factors $^{(21)}$, including money and time availabilities, access to grocery stores, transportation and neighbourhood safety ${ }^{(22)}$.

Therefore, based on data from the large E3N cohort study composed of 98995 women recruited from a national health insurance plan covering people working in the national education system, we derived two mutually exclusive dietary patterns from a latent class analysis (LCA) with the aim of studying cross-sectional associations between various socio-economic factors (individual and contextual factors) and a 'Healthy' dietary pattern. Socio-economic factors were considered one at a time, then simultaneously, with the objective of studying the interplays of such factors in relation to diet. The main aim of the present paper is to draw a more comprehensive picture of the complex relationships between diet and socio-economic factors.

\section{Methods}

\section{The E3N cobort study}

The E3N study is a French prospective cohort study of 98995 women recruited from a national health insurance plan covering people working in the national education system, initiated in $1990^{(23)}$. E3N is the French component of the European Prospective Investigation into Cancer and Nutrition (EPIC) ${ }^{(24)}$. Participants were sent questionnaires to update health-related information and newly diagnosed diseases every 2 to 3 years. The average follow-up response rate is $83 \%$ and, overall, the total loss to follow-up since 1990 is below 3\%.

\section{Study population}

Among the 74522 women with available dietary data in 1993, we excluded those who under- or over-reported energy intake ( $n$ 1491) as previously described ${ }^{(25)}$. These women were in the top and bottom $1 \%$ of the distribution of energy intake to BMR computed on the basis of age, height and weight. Thus 73031 women were included in the present cross-sectional study (mean age 52.9 (SD 6.7) years).

\section{Dietary data}

Dietary data were self-reported in 1993 using a previously validated diet history questionnaire ${ }^{(26)}$. Questions on 208 food items were asked for eight consumption occasions, from breakfast to after-dinner snacks (including occasions such as aperitifs before lunch and dinner), and included questions on consumption frequency (eleven categories, from 'never or less than once a month' to 'seven times a week') and portion sizes, allowing to compute quantities for each food or beverage in grams per day.

We derived a score of adherence to the national dietary guidelines from the dietary data ${ }^{(27)}$. It is based on quantitative and qualitative recommendations and includes thirteen components: fruit and vegetables; starchy foods including bread, cereal products, potatoes and legumes, with an emphasis on wholegrain foods; milk and dairy products; meat, poultry, seafood and eggs, with an emphasis on seafood; added fats with an emphasis on added vegetable fats; sweetened products; water and soda; alcohol; salt; and physical activity. At least 1 point is attributed to each component when the individual's behaviour is in agreement with the corresponding recommendation. The total score is obtained by adding up the points obtained for each component, taking the energy intake into account (points are proportionally deducted for individuals with energy intakes $5 \%$ greater than their estimated need). The score ranges from 0 (minimal adherence to the dietary guidelines) to 15 (maximal adherence to the dietary guidelines).

\section{Socio-economic information}

We considered both individual and contextual socioeconomic data in the E3N study. The following individual socio-economic variables were available in 1993: level of education; occupation in 1993 (currently working $v$. not working); the woman's income (based on the current professional activity reported by the women in 1992 or the last one if not currently working); number of children; and marital status (single $v$. in couple). The contextual socio-economic factors available in 1993 included: place of residence in 1993 (six categories: 'Paris and suburbs', 'North', 'West', 'East', 'Centre' and 'South'); size of the city of residence in 1993 (computed from the commune of residence (the smallest administrative unit in France) and categorized as: 'rural' (i.e. areas with fewer than 2000 inhabitants), 'quasirural' (i.e. areas with 2000 to 9999 inhabitants), 'quasi-urban' (i.e. areas with 10000 to 99999 inhabitants) and 'large urban' (i.e. areas with 100000 or more inhabitants)); and a deprivation index 'FDep99,(28) computed for each woman in 1993 from the information reported on her commune of 
residence. The 'FDep99' had been previously constructed at the commune level using four variables obtained from the 1999 population census and the tax authority's 2001 household income data ${ }^{(29)}$ : median household income; percentage of high-school graduates in the population aged 15 years or older; percentage of blue-collar workers in the active population; and unemployment rate.

We considered all of these factors because they had been found to be related to diet ${ }^{(11,30-32)}$. We additionally included two less explored contextual socio-economic variables because we estimated that they could help better characterize the socio-economic position of individuals: geographical area of birth (eight categories: 'Paris and suburbs', 'North', 'West', 'East', 'Centre', 'South', 'Dom-Tom' (overseas departments and territories of France) and 'Abroad'); and size of the place where working (two categories: ' $\leq 10000$ inhabitants' and '>10000 inhabitants').

\section{Individual characteristics}

Age, BMI, level of physical activity (in MET-h/week, where MET is metabolic equivalent of task) and smoking status (non-smoker, former smoker or current smoker) were self-reported in 1993 and included in the analysis. These factors were used for adjustment because they have been shown to be associated with diet as well as with socio-economic position ${ }^{(30,33-35)}$.

\section{Statistical analysis}

All statistical analyses were performed using the statistical software package SAS version 9.3. $P$ values of $<0.05$ were considered statistically significant.

\section{Latent class analysis to derive mutually exclusive dietary patterns}

To derive dietary patterns, we used LCA ${ }^{(36)}$. LCA is a statistical method used to identify a set of discrete, mutually exclusive, latent classes of individuals based on their responses to a set of observed categorical variables. It allows detecting patterns of unobserved or 'latent' subgroups or classes within a population. This method helps derive mutually exclusive groups that share similar characteristics (e.g. similar lifestyle patterns such as physical activity profiles or dietary patterns) ${ }^{(37)}$ and has recently been used in nutritional epidemiological studies ${ }^{(38-41)}$. The optimal number of classes with the optimal division for dietary data (tertiles, quartiles or quintiles) was assessed by four indicators: the lowest Bayesian information criterion; the Akaike Information Criterion; log likelihood; and the highest class membership probabilities, indicating the proportion of individuals expected to be classified in a given latent class. LCA methods were conducted with the LCA procedure developed by the Penn State University for SAS ${ }^{(36)}$.

To perform the LCA, the 208 food items available from the E3N dietary questionnaire were grouped into fifty-seven food groups as previously described ${ }^{(25)}$. Consumption of each food group, expressed in grams per day, was classified as non-consumers and as tertiles among the consumers. The corresponding categorical variables were then used to perform the LCA. Two dietary patterns were retained, labelled 'Healthy' ( $n$ 33 350) and 'Less Healthy' ( $n$ 39681), and were described in terms of food groups and nutrients (means and standard deviations, see below for descriptions). We chose to label our patterns 'Healthy' and 'Less Healthy' based on the characteristics of the E3N cohort study, E3N participants being more educated and healthconscious than the general population. Fisher's tests for continuous variables and $\chi^{2}$ tests for categorical variables were performed to study differences between patterns.

\section{Socio-economic factors associated with a healthy diet}

Individual and contextual socio-economic factors associated with a 'Healthy' diet were assessed by logistic regression models. Model 1 included the considered socioeconomic factor and was adjusted for age and energy intake. Model 2 was further adjusted for BMI, physical activity and smoking status. Model 3 was simultaneously adjusted for all socio-economic variables. We previously checked for the absence of multicollinearity, assessed with Spearman correlation coefficients. Odds ratios and 95\% confidence intervals were calculated.

\section{Interaction between area of residence and level of education}

Previous studies led in France ${ }^{(10,11)}$ suggested an interaction between level of education and area of residence, the South of France being of particular interest. We therefore investigated whether the association between level of education and diet varied according to the area of residence.

\section{Results}

\section{Dietary patterns}

The 'Healthy' pattern ( $v$. the 'Less healthy' pattern) was characterized by a larger consumption of foods considered as healthy such as fruits (271.7 (SD 185.7) v. 241.3 (SD 155.1) $\mathrm{g} / \mathrm{d}$ ), cooked vegetables (188.0 (SD 117.2) v. 161.5 (SD 89.8) $\mathrm{g} / \mathrm{d})$ and olive oil $(5.3(\mathrm{SD} 6.3) v .4 .3(\mathrm{sD} 5.0) \mathrm{g} / \mathrm{d}$ ); and a larger score of adherence to dietary guidelines ( $9 \cdot 6$ (SD 1.9) v. 8.5 (SD 2.3); Table 1).

On the other hand, the 'Less healthy' pattern was characterized by higher energy intake (10 125 (SD 2221) kJ/d (2419.9 (sD 530.8) kcal/d) v. 8201 (sD 2043) kJ/d (1960.1 (SD 488.2$) \mathrm{kcal} / \mathrm{d}$ ) and a higher consumption of foods considered unhealthy such as French fries (10.8 (SD 11.3) $v$. $5 \cdot 1$ (SD 9.4) g/d), pizza (25.4 (SD 22.3) v. 14.7 (SD 20.2) g/d), sandwiches (12.5 (sD 20.1) v. $5 \cdot 5(\mathrm{sD} 18 \cdot 2) \mathrm{g} / \mathrm{d})$ and processed meat (18.4 (sD 14.8) v. 7.8 (SD 11.7) g/d). We also compared the average consumption of fifteen food groups for women in each pattern with the average overall consumption in the study population (Fig. 1). The average consumption of fruits, 
Table 1 Characteristics of the population according to the two dietary patterns identified by a latent class analysis (E3N cohort study; $n$ 73031)

\begin{tabular}{|c|c|c|c|c|}
\hline & \multicolumn{2}{|c|}{$\begin{array}{l}\text { 'Healthy' pattern } \\
(n 33350)\end{array}$} & \multicolumn{2}{|c|}{$\begin{array}{c}\text { 'Less Healthy' } \\
\text { pattern } \\
(n 39681)\end{array}$} \\
\hline & Mean or $\%$ & SD & Mean or \% & SD \\
\hline \multicolumn{5}{|l|}{ Food group* $(\mathrm{g} / \mathrm{d})$} \\
\hline Fruits & $271 \cdot 7$ & $185 \cdot 7$ & $241 \cdot 3$ & $155 \cdot 1$ \\
\hline Cooked vegetables & $188 \cdot 0$ & $117 \cdot 2$ & 161.5 & $89 \cdot 8$ \\
\hline Cereals & 4.9 & 14.0 & 4.0 & 11.5 \\
\hline Fish & $28 \cdot 8$ & 24.6 & $28 \cdot 6$ & $19 \cdot 6$ \\
\hline Olive oil & $5 \cdot 3$ & $6 \cdot 3$ & 4.3 & $5 \cdot 0$ \\
\hline Tea & $195 \cdot 0$ & 299.2 & $180 \cdot 6$ & $264 \cdot 2$ \\
\hline French fries & $5 \cdot 1$ & 9.4 & $10 \cdot 8$ & $11 \cdot 3$ \\
\hline Pizza & 14.7 & $20 \cdot 2$ & $25 \cdot 4$ & $22 \cdot 3$ \\
\hline Sandwich & 5.5 & $18 \cdot 2$ & $12 \cdot 5$ & $20 \cdot 1$ \\
\hline Processed meat & $7 \cdot 8$ & $11 \cdot 7$ & $18 \cdot 4$ & 14.8 \\
\hline Meat & $54 \cdot 1$ & $36 \cdot 1$ & $60 \cdot 7$ & 31.9 \\
\hline Poultry & $23 \cdot 6$ & $17 \cdot 3$ & $25 \cdot 3$ & 14.4 \\
\hline Butter & $5 \cdot 1$ & $6 \cdot 7$ & $7 \cdot 6$ & $8 \cdot 2$ \\
\hline Wine & $80 \cdot 8$ & $129 \cdot 0$ & $104 \cdot 4$ & $127 \cdot 8$ \\
\hline Coffee & $281 \cdot 0$ & $279 \cdot 1$ & $299 \cdot 3$ & 257.9 \\
\hline \multicolumn{5}{|l|}{ Nutrient† $(\mathrm{g} / \mathrm{d})$} \\
\hline Energy (kJ/d) & 8201 & 2043 & 10125 & 2221 \\
\hline Energy $(\mathrm{kcal} / \mathrm{d})$ & $1960 \cdot 1$ & $488 \cdot 2$ & $2419 \cdot 9$ & $530 \cdot 8$ \\
\hline Carbohydrates & $209 \cdot 3$ & 68.0 & $255 \cdot 7$ & 68.0 \\
\hline Lipids & 77.4 & $23 \cdot 6$ & $98 \cdot 6$ & $25 \cdot 9$ \\
\hline Proteins & $90 \cdot 0$ & 24.5 & $104 \cdot 0$ & 23.9 \\
\hline Fibres & 24.1 & $8 \cdot 3$ & $25 \cdot 7$ & 7.4 \\
\hline Alcohol & 9.5 & 13.5 & $13 \cdot 4$ & $14 \cdot 0$ \\
\hline \multicolumn{5}{|l|}{ French dietary guidelines score } \\
\hline Dietary guidelines score $\ddagger$ & $9 \cdot 6$ & 1.9 & 8.5 & $2 \cdot 3$ \\
\hline Score $<8.31(\%)$ & $22 \cdot 6$ & - & $41 \cdot 8$ & - \\
\hline ore $<10.06(\%)$ & $34 \cdot 4$ & - & 31.8 & - \\
\hline Score $\geq 10.06$ & $43 \cdot 0$ & - & $26 \cdot 4$ & - \\
\hline
\end{tabular}

Values are means and their standard deviations or percentages. $P$ values were derived from Fisher's tests for continuous variables and from $\chi^{2}$ tests for categorical variables. The statistical tests provided $P<0.0001$ for each factor, except for 'Fish' where $P=0.3505$. Higher values are indicated in bold font.

*The fifteen most important foods groups that were used to derive the dietary patterns.

†These variables were used to describe the dietary patterns and were not used to derive the dietary patterns.

$\ddagger$ Higher dietary guidelines score means higher adherence to national nutritional recommendations.

cooked vegetables, cereals and olive oil was larger in women from the 'Healthy' pattern than in the overall population $(+6 \cdot 5,+8 \cdot 3,+10 \cdot 9$ and $+11 \cdot 2 \%$, respectively). The average consumption of French fries, pizza, sandwiches, processed meat, butter and wine was greater in women from the 'Less healthy' pattern than in the overall population $(+31 \cdot 4,+23 \cdot 7,+34 \cdot 3,+36 \cdot 1,+17 \cdot 4$ and $+11 \cdot 5 \%$, respectively).

\section{Participant characteristics}

Women from the 'Healthy' pattern were older than women from the 'Less Healthy' pattern (54.3 (SD 6.8) v. 51.8 (SD 6.3) years old), had a comparable BMI (22.9 (SD 3.3) v. 23.0 $(\mathrm{sD} 3 \cdot 2) \mathrm{kg} / \mathrm{m}^{2}$ ) and a similar mean level of physical activity (49.3 (SD 52.5) v. $49 \cdot 2$ (SD 48.7) MET-h/week). No difference between the proportions of overweight and obese women was observed between the two groups (19.9 v. 20.0\%). The smoking status of women from the 'Healthy' pattern and women from the 'Less healthy' pattern was quite comparable, with 13.2 and $13.7 \%$ being smokers in the two patterns, respectively.

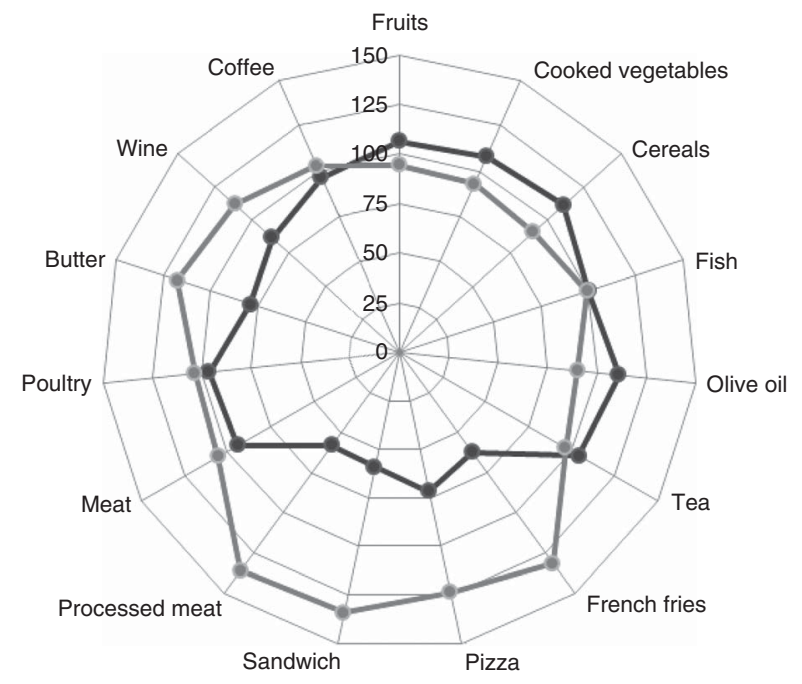

Fig. 1 Description of the two dietary patterns (E3N cohort study, $n$ 73031): comparison of the average consumption of the fifteen main food groups between women in the 'Healthy' pattern (--) and women in the 'Less Healthy' pattern (--). The average consumption in the pattern is expressed as a percentage of the average consumption of the entire population

\section{Individual and contextual socio-economic factors associated with the 'Healthy' pattern}

Table 2 presents the associations between the 'Healthy' dietary pattern and ten individual and contextual socioeconomic factors.

Model 1 shows the age- and energy-adjusted association between each socio-economic factor and adherence to a 'Healthy' dietary pattern. In model 2 further adjusted for physical activity, BMI and smoking status, all associations remained similar to model 1 . Regarding individual socioeconomic factors taken into account one by one, having one or more children (OR $=0.86 ; 95 \%$ CI 0.81, 0.92 and $\mathrm{OR}=0.63$; $95 \%$ CI $0.60,0.67$ for one child and three children, respectively, $v$. no children), having an intermediate level of education ( $\mathrm{OR}=0 \cdot 84 ; 95 \%$ CI 0.80, 0.89 $v$. less than a high-school diploma completed), having an intermediate income $(\mathrm{OR}=0.91 ; 95 \%$ CI $0.86,0.97 v$. lowest income with less than $€ 16963 /$ year) and being in a couple $(\mathrm{OR}=0.71 ; 95 \%$ CI $0.68,0.74 v$. single) were associated with a lower probability of following the 'Healthy' pattern. No association was found between occupation status and following a 'Healthy' diet.

Regarding contextual socio-economic factors, living in quasi-urban or large urban areas $(\mathrm{OR}=1 \cdot 08 ; 95 \% \mathrm{CI} 1.03$, $1 \cdot 14$ and $\mathrm{OR}=1 \cdot 26 ; 95 \% \mathrm{CI} 1 \cdot 19,1.33$, respectively, $v$. rural areas) and working in cities with more than 10000 inhabitants $(\mathrm{OR}=1.14 ; 95 \% \mathrm{CI} 1.08,1.19 v$. cities with 10000 inhabitants or fewer) were associated with a higher probability of following the 'Healthy' pattern. Living in deprived areas $(\mathrm{OR}=0.90 ; 95 \%$ CI $0.87,0.94 v$. less deprived areas with FDep99 <-0.52) was associated with a lower probability of following the 'Healthy pattern'. 
Table 2 Socio-economic factors and individual characteristics associated with the 'Healthy' dietary pattern (E3N cohort study, $n$ 73031)

\begin{tabular}{|c|c|c|c|c|c|c|c|c|}
\hline & \multicolumn{2}{|c|}{$\begin{array}{l}\text { 'Healthy' pattern } \\
(n 33350)\end{array}$} & \multicolumn{2}{|c|}{ Model 1} & \multicolumn{2}{|c|}{ Model 2} & \multicolumn{2}{|c|}{ Model 3} \\
\hline & $n$ & $\%$ & $\mathrm{OR}^{*}$ & $95 \% \mathrm{Cl}$ & $\mathrm{OR}^{*}$ & $95 \% \mathrm{Cl}$ & $\mathrm{OR}^{*}$ & $95 \% \mathrm{Cl}$ \\
\hline \multicolumn{9}{|l|}{ Socio-economic individual factors } \\
\hline \multicolumn{9}{|l|}{ Level of education } \\
\hline$<$ High-school diploma & 4130 & $50 \cdot 5$ & \multicolumn{2}{|r|}{ Ref. } & & \\
\hline Up to 2 university years & 17427 & 44.9 & 0.84 & $0.80,0.89$ & \multicolumn{2}{|r|}{$\begin{array}{l}\text { Ref. } \\
0.80 \quad 0.89\end{array}$} & \multicolumn{2}{|r|}{$\begin{array}{l}\text { Ref. } \\
0.79,0.90\end{array}$} \\
\hline$>2$ university years & 11793 & $45 \cdot 2$ & 0.96 & $0.90,1.01$ & 0.96 & $0.90,1.01$ & 0.89 & $0.83,0.95$ \\
\hline Occupation & & & & & & & & \\
\hline No & 12348 & $54 \cdot 1$ & & Ref. & & Ref. & & Ref. \\
\hline Yes & 21002 & $41 \cdot 8$ & 1.03 & $0.98,1.08$ & 1.03 & $0.98,1.08$ & 1.22 & $1.06,1.40$ \\
\hline Woman's income (n 62713; €/year) & $(n 2 \varepsilon$ & & & & & & & \\
\hline$<16963$ & 3497 & $45 \cdot 1$ & & Ref. & & Ref. & & Ref. \\
\hline $16963-17713$ & 8789 & $44 \cdot 0$ & 0.95 & $0.89,1.00$ & 0.95 & $0.89,1.00$ & 1.06 & $0.99,1.14$ \\
\hline $17713-24156$ & 6599 & $45 \cdot 7$ & 0.91 & $0.86,0.97$ & 0.91 & $0.86,0.97$ & 1.02 & $0.95,1.09$ \\
\hline$\geq 24156$ & 9305 & $45 \cdot 2$ & 1.05 & $0.99,1.11$ & 1.05 & $0.99,1.12$ & 1.08 & $1.01,1.16$ \\
\hline Number of children & & & & & & & & \\
\hline 0 & 4743 & $54 \cdot 7$ & & Ref. & & Ref. & & Ref. \\
\hline 1 & 5704 & $49 \cdot 8$ & 0.87 & $0.81,0.92$ & 0.86 & $0.81,0.92$ & 0.94 & $0.88,1.00$ \\
\hline 2 & 13699 & 43.2 & 0.69 & $0.65,0.73$ & 0.69 & $0.65,0.72$ & 0.77 & $0.73,0.81$ \\
\hline$\geq 3$ & 9204 & 43.4 & 0.64 & $0.60,0.67$ & 0.63 & $0.60,0.67$ & 0.70 & $0.66,0.75$ \\
\hline Marital status & & & & & & & & \\
\hline Single & 6555 & 53.7 & & Ref. & & Ref. & & Ref. \\
\hline Couple & 26795 & $44 \cdot 0$ & 0.72 & $0.68,0.75$ & 0.71 & $0.68,0.74$ & 0.79 & $0.75,0.83$ \\
\hline Socio-economic contextual factors & & & & & & & & \\
\hline Area of birth & & & & & & & & \\
\hline South & 10178 & $49 \cdot 0$ & & Ref. & & Ref. & & Ref. \\
\hline West & 3308 & 41.9 & 0.73 & $0.69,0.78$ & 0.74 & $0.69,0.78$ & 0.88 & $0.81,0.94$ \\
\hline North & 4196 & 41.2 & 0.74 & $0.70,0.78$ & 0.74 & $0.71,0.79$ & 0.83 & $0.78,0.89$ \\
\hline East & 5037 & 43.9 & 0.78 & $0.74,0.82$ & 0.78 & $0.74,0.82$ & 0.84 & $0.79,0.90$ \\
\hline Centre & 2878 & $44 \cdot 1$ & 0.80 & $0.76,0.86$ & 0.81 & $0.76,0.86$ & 0.87 & $0.81,0.94$ \\
\hline Paris and suburbs & 4930 & $46 \cdot 1$ & 0.89 & $0.85,0.94$ & 0.90 & $0.85,0.94$ & 0.89 & $0.84,0.95$ \\
\hline Dom-Tom & 101 & 51.5 & 0.89 & $0.65,1.22$ & 0.90 & $0.65,1.23$ & 0.90 & $0.66,1.24$ \\
\hline Abroad & 2722 & 51.6 & 1.03 & $0.96,1.10$ & 1.04 & $0.97,1.11$ & 1.06 & $0.99,1.13$ \\
\hline Area of residence & & & & & & & & \\
\hline South & 12728 & 49.7 & & Ref. & & Ref. & & Ref. \\
\hline West & 3163 & 39.7 & 0.70 & $0.66,0.74$ & 0.70 & $0.66,0.74$ & 0.78 & $0.72,0.83$ \\
\hline North & 3775 & $40 \cdot 2$ & 0.74 & $0.70,0.78$ & 0.74 & $0.71,0.78$ & 0.84 & $0.79,0.91$ \\
\hline East & 4439 & $43 . \overline{2}$ & 0.80 & $0.75,0.84$ & 0.80 & $0.76,0.84$ & 0.90 & $0.84,0.96$ \\
\hline Centre & 2564 & $43 \cdot 3$ & 0.80 & $0.75,0.85$ & 0.80 & $0.75,0.85$ & 0.88 & $0.82,0.95$ \\
\hline Paris and suburbs & 6681 & $48 \cdot 1$ & 0.98 & $0.93,1.02$ & 0.98 & $0.94,1.03$ & 1.01 & $0.96,1.07$ \\
\hline Size of the agglomeration of residence & & & & & & & & \\
\hline Rural (<2000 inhabitants) & 5075 & $42 \cdot 7$ & & Ref. & & Ref. & & Ref. \\
\hline Quasi-rural (2000 to 9999 inhabitants) & 8169 & 43.0 & 0.98 & $0.93,1.03$ & 0.98 & $0.93,1.03$ & 0.96 & $0.91,1.01$ \\
\hline Quasi-urban (10000 to 99999 inhabitants) & 13254 & $46 \cdot 3$ & 1.08 & $1.03,1.14$ & 1.08 & $1.03,1.14$ & 0.99 & $0.94,1.04$ \\
\hline Large urban areas ( $\geq 100000$ inhabitants) & 6852 & $50 \cdot 5$ & 1.26 & $1.19,1.33$ & 1.26 & $1.19,1.33$ & 1.08 & $1.02,1.15$ \\
\hline Deprivation index (FDep99) & & & & & & & & \\
\hline$<-0.52$ (less deprived) & 11254 & $46 \cdot 7$ & & Ref. & & Ref. & & Ref. \\
\hline$-0.52-0.21$ & 11009 & $45 \cdot 7$ & 0.95 & $0.91,0.99$ & 0.95 & $0.91,0.99$ & 1.00 & $0.96,1.05$ \\
\hline$\geq 0.21$ & 11087 & $44 \cdot 6$ & 0.90 & $0.87,0.94$ & 0.90 & $0.87,0.94$ & 1.00 & $0.95,1.04$ \\
\hline Size of the working agglomeration ( $n 39096$ ) & $(n 15$ & & & & & & & \\
\hline$\leq 10000$ inhabitants & 4406 & 37.7 & & Ref. & & Ref. & & Ref. \\
\hline$>10000$ inhabitants & 11541 & $42 \cdot 1$ & 1.14 & $1.08,1.19$ & 1.14 & $1.08,1.19$ & 1.03 & $0.97,1.08$ \\
\hline Individual characteristics & & & & & & & & \\
\hline Age (years) & & & & & & & & \\
\hline$\leq 47.2$ & 6361 & $34 \cdot 8$ & & Ref. & & Ref. & & Ref. \\
\hline $47 \cdot 2-51 \cdot 7$ & 7325 & $40 \cdot 1$ & 1.22 & $1.16,1.27$ & 1.22 & $1 \cdot 16,1.28$ & 1.20 & $1 \cdot 14,1.25$ \\
\hline $51 \cdot 7-57 \cdot 7$ & 8988 & 49.2 & 1.78 & $1.70,1.86$ & 1.78 & $1.70,1.86$ & 1.72 & $1.64,1.81$ \\
\hline$>57.7$ & 10676 & 58.4 & 2.40 & $2.30,2.52$ & 2.41 & $2.30,2.53$ & 2.21 & $2.07,2.35$ \\
\hline BMI $\left(\mathrm{kg} / \mathrm{m}^{2}\right)$ & & & & & & & & \\
\hline$<18.5$ & 1332 & 55.4 & 1.41 & $1.29,1.55$ & 1.41 & $1.29,1.55$ & 1.36 & $1.24,1.49$ \\
\hline $18 \cdot 5-25$ & 25372 & $45 \cdot 3$ & & Ref. & & Ref. & & Ref. \\
\hline $25-30$ & 5488 & 45.9 & 0.98 & $0.93,1.02$ & 0.98 & $0.93,1.02$ & 0.99 & $0.95,1.04$ \\
\hline$\geq 30$ & 1158 & $44 \cdot 2$ & 1.09 & $0.99,1.19$ & $1 \cdot 10$ & $1.00,1.20$ & 1.09 & $0.99,1.19$ \\
\hline Physical activity (MET-h/week) & & & & & & & & \\
\hline$\leq 22.9$ & 8798 & $48 \cdot 1$ & & Ref. & & Ref. & & Ref. \\
\hline $22 \cdot 9-37.8$ & 8234 & $45 \cdot 2$ & 0.89 & $0.85,0.93$ & 0.89 & $0.85,0.93$ & 0.89 & $0.85,0.93$ \\
\hline $37 \cdot 8-60 \cdot 7$ & 7967 & $43 . \overline{6}$ & 0.85 & $0.81,0.89$ & 0.84 & $0.80,0.88$ & 0.84 & $0.80,0.88$ \\
\hline$>60 \cdot 7$ & 8351 & $45 \cdot 8$ & 0.92 & $0.88,0.96$ & 0.92 & $0.88,0.96$ & 0.92 & $0.87,0.96$ \\
\hline
\end{tabular}




\begin{tabular}{|c|c|c|c|c|c|c|c|c|}
\hline & \multicolumn{2}{|c|}{$\begin{array}{l}\text { 'Healthy' pattern } \\
(\text { ( } 33350)\end{array}$} & \multicolumn{2}{|c|}{ Model 1} & \multicolumn{2}{|c|}{ Model 2} & \multicolumn{2}{|c|}{ Model 3} \\
\hline & $n$ & $\%$ & $\mathrm{OR}^{*}$ & $95 \% \mathrm{Cl}$ & $\mathrm{OR}^{*}$ & $95 \% \mathrm{Cl}$ & $\mathrm{OR}^{*}$ & $95 \% \mathrm{Cl}$ \\
\hline \multicolumn{9}{|l|}{ Smoking status } \\
\hline Non-smoker & 18629 & $47 \cdot 2$ & & Ref. & & Ref. & & Ref. \\
\hline Former smoker & 10311 & 43.4 & 0.90 & $0.87,0.93$ & 0.90 & $0.87,0.94$ & 0.89 & $0.85,0.92$ \\
\hline Smoker & 4410 & 44.7 & 0.99 & $0.94,1.04$ & 0.99 & $0.94,1.04$ & 0.92 & $0.87,0.97$ \\
\hline
\end{tabular}

Dom-Tom, overseas departments and territories of France; MET, metabolic equivalent of task; ref., reference category.

Model 1: adjusted for age and energy intake.

Model 2: model 1 adjusted for physical activity, smoking status and BMI.

Model 3: multi-adjusted model.

*An OR above 1 corresponds to a higher probability of following the 'Healthy' pattern; significant OR and $95 \% \mathrm{Cl}$ are indicated in bold font.

Women born or living in areas of France other than the South were less likely to follow a 'Healthy' diet.

Moreover, in terms of individual characteristics, being older or obese was associated with a higher probability of following the 'Healthy' pattern (OR $=2.41$; $95 \%$ CI 2.30, 2.53 for fourth $v$. first quartile of age and $\mathrm{OR}=1 \cdot 10 ; 95 \%$ CI $1 \cdot 00$, 1.20 for obese $v$. normal BMI, respectively), whereas a high physical activity level (OR $=0.92 ; 95 \% \mathrm{CI} 0.88,0.96 v$. the lowest physical activity level with $22.9 \mathrm{MET}-\mathrm{h} /$ week or less) or being a former smoker (OR $=0.90 ; 95 \%$ CI 0.87, $0.94 v$. no smoker) was associated with a lower probability of following the 'Healthy' dietary pattern.

The magnitudes of the associations suggested that having had three or more children was the strongest predictor (unadjusted on other socio-economic factors) of not following a healthy diet.

In model 3, where all socio-economic factors were adjusted for, most previous associations were only slightly attenuated. Changes that occurred after multiple adjustment were as follows: being more educated ( $\mathrm{OR}=0.89$; $95 \% \mathrm{CI}$ $0.83,0.95 v$. less than a high-school diploma completed) was associated with a lower probability of following a 'Healthy' pattern; and having an occupation $(\mathrm{OR}=1 \cdot 22 ; 95 \% \mathrm{CI} 1.06$, $1.40 v$. no occupation) and a higher income $(\mathrm{OR}=1.08 ; 95 \%$ CI 1.01, $1.16 v$. lowest income with less than $€ 16963 /$ year) were associated with a higher probability of following the 'Healthy' pattern. Deprivation index and size of the agglomeration where working were no longer associated with diet after multiple adjustment.

\section{Interaction between the area of residence and the level of education}

We observed an interaction between the area of residence (South $v$. other areas of France) and the level of education $(P=0 \cdot 01)$. In the South of France, women with no highschool diploma were more likely to follow a healthy diet than women having a level of education greater than two university years $(\mathrm{OR}=1 \cdot 14 ; 95 \% 1 \cdot 04,1 \cdot 26)$, whereas no difference was observed between extreme categories of level of education in the other areas (OR $=1 \cdot 00 ; 05 \% \mathrm{CI}$ $0.93,1.07)$.

\section{Discussion}

In the large $\mathrm{E} 3 \mathrm{~N}$ female cohort study where detailed information on diet and socio-economic status was collected, adherence to a 'Healthy' diet was shown to be highly dependent on various individual and contextual socio-economic factors.

Our main objective was to study the associations between a 'Healthy' diet and socio-economic factors (individual and contextual ones) using two complementary analytical approaches. The first one separately evaluated each socioeconomic factor, allowing us to examine the issue of social inequities in diet across a variety of dimensions. The second accounted for all socio-economic factors simultaneously, highlighting all the independent socio-economic factors associated with following a healthy diet.

In the fully adjusted model, all studied socio-economic and individual characteristics were associated with diet, with the exception of the deprivation index and the size of the agglomeration where working.

\section{Socio-economic individual factors and diet}

\section{Level of education and diet}

In contrast to our study, Vlismas et al. ${ }^{(42)}$, Kesse-Guyot et $a l^{(43)}$ and most of the literature have reported that people with high education levels have healthier dietary habits than those with a lower level of education. Despite the large socio-economic variability, it must be emphasized that the E3N women are more educated than the general population and that this could explain part of the results. Otherwise, an interaction between the level of education and the area of residence has been previously suggested in France ${ }^{(10,11)}$. On one hand, Wyndels et al. ${ }^{(11)}$ did not observe any association between level of education and nutritional habits in southwestern France whereas a positive association between education level and healthy dietary habits was observed in northern and north-eastern France. On the other hand, Roos et al. ${ }^{(10)}$ suggested that in regions where consumption of healthy products such as fruit and vegetables is more common, lower social classes tend to consume more than higher social classes. Our results are in agreement with those 
results. Indeed, we observed an interaction between the area of residence (South $v$. other areas of France) and the level of education. This interaction strengthens our hypothesis that the socio-economic-diet associations cannot solely be characterized by individual socio-economic factors such as the level of education and that it is essential to consider several socio-economic factors together.

\section{Income, occupation and diet}

In the fully adjusted model, women with higher income were more likely to follow a healthy diet and our results are in agreement with previous reports ${ }^{(11,32)}$.

Occupational status has not been frequently studied as a binary variable. In our study, active women were more likely to follow a healthy diet. Bertin et al. ${ }^{(30)}$ reported similar results, with inactive women (excluding retired women) more likely to be adherent to 'traditional' (including meat, bread, cheese and alcoholic beverages) and 'sandwiches' patterns and less prone to be adherent to a 'diversified' pattern.

\section{Marital status and diet}

In our study, women being in a couple were more likely to follow a healthy pattern, in agreement with a report where single women were less prone to follow national dietary guidelines $^{(44)}$.

\section{Socio-economic contextual factors and diet}

Areas of birth, residence and work in relation to diet We reported that the place of birth and the place of residence were both associated with diet, with women born and living in the West, North, East or Centre of France having lower probability to follow a healthy diet than women born and living in the South. This agrees with previous studies in the literature that demonstrated the existence of a north-south gradient in France, with southern populations characterized by higher consumption of fruit, vegetables and olive oil ${ }^{(45-47)}$. It has also been reported that French women living in the South of France were more likely to be adherent to a 'diversified' pattern and less prone to be adherent to a 'sandwiches' pattern ${ }^{(30)}$. Regarding Paris and suburbs, there was an inverse association between being born there and following a healthy diet, but no association was observed for living there.

Women living in urban areas were more prone to follow a healthy diet than their counterparts living in rural areas or smaller cities. Other studies have similarly observed that in France, with globalization and changes in diet and physical activity habits, rural populations are nowadays more likely to be obese ${ }^{(48)}$ and to follow unhealthy $\operatorname{diets}^{(43)}$. It has also been reported that women living in urban areas were less likely to follow a 'traditional' diet that includes several unhealthy foods ${ }^{(30)}$.
Deprivation index and diet

The deprivation index reflects the contextual environment and we hypothesized that it was the best marker of access to healthy foods available in our study ${ }^{(49-51)}$. We did not observe any association between deprivation index and diet in the fully adjusted model. Although associations have been reported between area characteristics and residents' diets ${ }^{(52,53)}$, these associations have also been challenged $^{(31)}$. There was an association between the deprivation index and diet in the univariate model, suggesting that the deprivation index was encapsulating the composition effect of other socio-economic variables.

\section{Individual characteristics and diet}

While our results were consistent with those from previous studies on smoking status and age, with non-smoking and older women being more likely to follow a healthy diet ${ }^{(43)}$, we observed unexpected results for physical activity ${ }^{(54)}$. Our results showed that healthy behaviours were not always positively correlated, which underlines the existence of complex interactions between socio-economic factors and healthy behaviours. An alternative explanation is that these results could be due to reverse causality which cannot be completely ruled out.

The strongest gradient was observed between age and the odds of following a healthy diet, with women older than $57 \cdot 7$ years having a $2 \cdot 2$-fold higher probability to follow a healthy diet than women younger than 47.2 years. It seems of major importance to better understand the mechanisms involved in this association to provide more effective public health strategies adapted to different population groups. Younger women may have less time to cook because of their professional activity and this should be considered in prevention strategies. Younger women may also be less health-conscious than older women.

The second strongest gradient was observed between the number of children and the odds of following a healthy diet, with women with children being less prone to follow a healthy diet than women without children. Few studies have previously reported on this relationship: Bertin et al. ${ }^{(30)}$ showed that single women with a child were more adherent to a 'sandwiches' pattern and Elstgeest et al. ${ }^{(55)}$ showed that women living in a family had lower scores on the 'Mediterranean-style' and 'fruit' patterns. As suggested previously ${ }^{(55)}$, our results could be explained by the increased demands of family responsibilities for the women and less time to spend on food decisions and preparation. Familial context seems to play an important role in dietary profiles and it appears important to take it into account.

\section{Limitations and strengths}

The current work has some limitations. As the study was cross-sectional, causality cannot be inferred. Nevertheless we were able to provide a large overview of the associations between the socio-economic environment and diet. 
We acknowledge that the socio-economic data used here do not encompass the entire socio-economic status. For example, childhood socio-economic environment was not accounted for. Hare-Bruun et ll $^{(6)}$ found that the childhood socio-economic status was a determinant of adult female dietary patterns. As socio-economic factors may operate at different levels and through different causal pathways throughout the life course, obtaining socio-economic information from childhood has been reported as important ${ }^{(18)}$. Some contextual socio-economic data such as access to grocery stores, transportation and neighbourhood safety were not available in the $\mathrm{E} 3 \mathrm{~N}$ cohort and consequently could not be studied. We also missed having complete data on retirement and household income, and we used the occupational status and the individual income as proxies.

Moreover, measurement bias could exist, as participants' abilities to report their diet might be influenced by socioeconomic factors. Under-reporting has, for example, been associated with both lower and higher levels of education. It can be explained by poor literacy skills in lower social classes and it may be connected to the healthy image of foods and the wish to convey a socially desirable image in higher social classes ${ }^{(56)}$. Also, women in the E3N study are more health-conscious and more homogeneous concerning educational level and occupation than the general population. E3N is composed mainly of female teachers but work such as housekeeper, director and farmer for example are also represented, which ensures us a large socio-economic variability. Therefore, our results could not be directly extrapolated to the general population. However, we have still been able to observe a large socio-economic variability and strong gradients of associations between socioeconomic factors and diet in our selected population. We assume that these associations would have been even stronger in the general population where a greater variability in diet and socio-economic environment exists.

On the other hand, our work also has several strengths. The present study has a strong statistical power. We were able to highlight numerous associations between diet and the socio-economic environment. Even if our results cannot be directly generalized to the general population, they reinforce the idea of a true complex socio-economic gradient in the population and of large socio-economic disparities even within groups of rather high socio-economic status. We derived two dietary patterns using LCA, an underused and innovative statistical method in nutritional epidemiology. The two patterns obtained were in accordance with those derived with traditional methods ${ }^{(3,57)}$ and had the advantage of being mutually exclusive. In our iterative tests to select the optimal number of patterns, it appeared that an LCA with four dietary patterns was an option; but on closer examination, two of them were actually a moderate version of either the 'Healthy' or the 'Less Healthy' pattern with similar characteristics. Therefore we decided to keep only two dietary patterns, 'Healthy' and 'Less Healthy', with more statistical power to run accurate analyses. In nutritional epidemiology, LCA has already been used to derive behavioural patterns in relation to $\operatorname{diet}^{(39,58,59)}$ and also to derive dietary patterns based on detailed food consumption $^{(38,40,41,60,61)}$. Nevertheless, ours is the first study, using this methodology, with so many details on both dietary and socio-economic information in such a large population. To the best of our knowledge, the present study is also the first one to investigate the association between a deprivation index and diet in a French context. Furthermore, we were able to simultaneously study various individual and contextual socio-economic factors. Consistently with other studies $^{(18,20,30,62,63)}$, our results have shown the need to consider more than one socio-economic factor, especially the commonly used 'level of education', to capture the complex relationships between the socio-economic environment and diet. Each socio-economic factor has been suggested to reflect different underlying social processes ${ }^{(20)}$. Socio-economic environment has to be considered as a whole network in which individual and contextual factors act together. Understanding this network will help us to better understand the adoption of dietary patterns and develop efficient nutritional recommendations.

\section{Conclusion}

In conclusion, we confirmed that socio-economic environment is a complex network composed of individual and contextual factors and is strongly associated with dietary patterns. We observed that, when investigating their potential impact on diet, socio-economic factors are not interchangeable, and that the kind of data included in the analysis is of importance. In our study, being older, less educated, having no children, having an occupation, having a high income, being single, and living in urban areas or in the South of France were associated with a healthy diet. Our results highlight the need for considering several individual and contextual socio-economic variables simultaneously, rather than a single factor such as the level of education, in order to better account for the numerous dimensions of socio-economic status. Based on our findings, we suggest future public health and nutritional prevention strategies be modulated according to the individual's socio-economic disadvantage, defined both by the individual's characteristics and the contextual environment, as it can lead to inequalities in access to healthy foods. Further studies examining the impact of socio-economic environment on the evolution of dietary patterns throughout time are now needed.

\section{Acknowledgements}

Acknowledgements: The authors are grateful to all participants for providing the data used in the E3N study. Financial support: The E3N cohort is being carried out with the financial support of 'Mutuelle Générale de l'Education 
Nationale' (MGEN); European Community; French League against Cancer (LNCC); Gustave Roussy Institute (GR); and French Institute of Health and Medical Research (Inserm). This present work was supported by a grant from the French National Cancer Institute (INCa) and a grant from the World Cancer Research Fund (WCRF; grant number 2015/1389). A.A. is supported by a doctoral grant from INCa. The MGEN, European Community, LNCC, GR, Inserm, INCa and WCRF had no role in the design, analysis or writing of this article. Conflict of interest: None. Authorship: A.A., F.C.-C., M.-.C.B.-R., and G.F. contributed to the data collection; A.A. and G.F. formulated the research questions and designed the research; A.A. performed the statistical analysis and primary manuscript preparation; A.A. and G.F. wrote the paper; G.F. has primary responsibility for the final content; G.S., C.D., G.R., C.D.P., M.-C.B.-R. and F.C.-C. reviewed the paper and revised it critically. All authors read and approved the final manuscript. Ethics of buman subject participation: This study was conducted according to the guidelines laid down in the Declaration of Helsinki and all procedures involving human subjects were approved by the French National Commission for Computerized Data and Individual Freedom (CNIL). All women signed a letter of informed consent to allow their data to be stored, as required by the CNIL.

\section{References}

1. Jacobs DR Jr (2014) What comes first: the food or the nutrient? Executive summary of a symposium. J Nutr 144, 4 Suppl., 543S-546S.

2. Kant AK (2004) Dietary patterns and health outcomes. J Am Diet Assoc 104, 615-635.

3. Dietary Guidelines Advisory Committee (2015) Scientific Advisory Report of the 2015 Dietary Guidelines Advisory Committee. Advisory Report to the Secretary of Health and Human Services and the Secretary of Agriculture. Washington, DC: US Department of Agriculture, Agricultural Research Service.

4. World Cancer Research Fund/American Institute for Cancer Research (2009) Food, Nutrition, Physical Activity, and the Prevention of Cancer: A Global Perspective. Washington, DC: AICR.

5. Giskes K, Avendano M, Brug J et al. (2010) A systematic review of studies on socioeconomic inequalities in dietary intakes associated with weight gain and overweight/obesity conducted among European adults. Obes Rev 11, 413-429.

6. Hare-Bruun H, Togo P, Andersen LB et al. (2011) Adult food intake patterns are related to adult and childhood socioeconomic status. J Nutr 141, 928-934.

7. Leech RM, McNaughton SA \& Timperio A (2014) The clustering of diet, physical activity and sedentary behavior in children and adolescents: a review. Int J Behav Nutr Phys Act 11, 4.

8. Pechey R, Jebb SA, Kelly MP et al. (2013) Socioeconomic differences in purchases of more vs. less healthy foods and beverages: analysis of over 25,000 British households in 2010. Soc Sci Med 92, 22-26.

9. Whichelow MJ \& Prevost AT (1996) Dietary patterns and their associations with demographic, lifestyle and health variables in a random sample of British adults. Br J Nutr 76, 17-30.

10. Roos G, Johansson L, Kasmel A et al. (2001) Disparities in vegetable and fruit consumption: European cases from the north to the south. Public Health Nutr 4, 35-43.
11. Wyndels K, Dallongeville J, Simon C et al. (2011) Regional factors interact with educational and income tax levels to influence food intake in France. Eur J Clin Nutr 65, 1067-1075.

12. Mackenbach JP, Stirbu I, Roskam AJ et al. (2008) Socioeconomic inequalities in health in 22 European countries. $N$ Engl J Med 358, 2468-2481.

13. Menvielle G, Leclerc A, Chastang JF et al. (2007) Changes in socioeconomic inequalities in cancer mortality rates among French men between 1968 and 1996. Am J Public Health 97, 2082-2087.

14. Windenberger F, Rican S, Jougla E et al. (2012) Spatiotemporal association between deprivation and mortality: trends in France during the nineties. Eur J Public Health 22, 347-353.

15. Marmot M, Allen J, Bell R et al. (2012) WHO European review of social determinants of health and the health divide. Lancet 380, 1011-1029.

16. Agardh E, Allebeck P, Hallqvist J et al. (2011) Type 2 diabetes incidence and socio-economic position: a systematic review and meta-analysis. Int J Epidemiol 40, 804-818.

17. Espelt A, Borrell C, Roskam AJ et al. (2008) Socioeconomic inequalities in diabetes mellitus across Europe at the beginning of the 21st century. Diabetologia 51, 1971-1979.

18. Braveman PA, Cubbin C, Egerter S et al. (2005) Socioeconomic status in health research: one size does not fit all. JAMA 294, 2879-2888.

19. Lassale C, Galan P, Castetbon K et al. (2013) Differential association between adherence to nutritional recommendations and body weight status across educational levels: a cross-sectional study. Prev Med 57, 488-493.

20. Turrell G, Hewitt B, Patterson C et al. (2003) Measuring socioeconomic position in dietary research: is choice of socioeconomic indicator important? Public Health Nutr 6, 191-200.

21. Liberatos P, Link BG \& Kelsey JL (1988) The measurement of social class in epidemiology. Epidemiol Rev 10, 87-121.

22. Darmon N \& Drewnowski A (2008) Does social class predict diet quality? Am J Clin Nutr 87, 1107-1117.

23. Clavel-Chapelon F, van Liere MJ, Giubout C et al. (1997) E3N, a French cohort study on cancer risk factors. E3N Group. Etude Epidemiologique aupres de femmes de l'Education Nationale. Eur J Cancer Prev 6, 473-478.

24. Riboli E \& Kaaks R (1997) The EPIC Project: rationale and study design. European Prospective Investigation into Cancer and Nutrition. Int J Epidemiol 26, Suppl. 1, S6-S14.

25. Cottet V, Touvier M, Fournier A et al. (2009) Postmenopausal breast cancer risk and dietary patterns in the E3N-EPIC prospective cohort study. Am J Epidemiol 170, 1257-1267.

26. van Liere MJ, Lucas F, Clavel F et al. (1997) Relative validity and reproducibility of a French dietary history questionnaire. Int J Epidemiol 26, Suppl. 1, S128-S136.

27. Estaquio C, Kesse-Guyot E, Deschamps V et al. (2009) Adherence to the French Programme National Nutrition Sante Guideline Score is associated with better nutrient intake and nutritional status. J Am Diet Assoc 109, 1031-1041.

28. Rey G, Jougla E, Fouillet A et al. (2009) Ecological association between a deprivation index and mortality in France over the period 1997-2001: variations with spatial scale, degree of urbanicity, age, gender and cause of death. BMC Public Health 9, 33 .

29. Institut National de la Statistique et des Etudes Economiques (2016) Homepage http://www.insee.fr/ (accessed January 2017).

30. Bertin M, Touvier M, Dubuisson C et al. (2016) Dietary patterns of French adults: associations with demographic, socio-economic and behavioural factors. J Hum Nutr Diet 29, 241-254.

31. Macintyre S (2007) Deprivation amplification revisited; or, is it always true that poorer places have poorer access to resources for healthy diets and physical activity? Int J Behav Nutr Phys Act $\mathbf{4}, 32$. 
32. Perrin AE, Dallongeville J, Ducimetiere P et al. (2005) Interactions between traditional regional determinants and socio-economic status on dietary patterns in a sample of French men. Br J Nutr 93, 109-114.

33. Beenackers MA, Kamphuis CB, Giskes K et al. (2012) Socioeconomic inequalities in occupational, leisure-time, and transport related physical activity among European adults: a systematic review. Int J Behav Nutr Phys Act 9, 116.

34. Cameron AJ, Spence AC, Laws R et al. (2015) A review of the relationship between socioeconomic position and the early-life predictors of obesity. Curr Obes Rep 4, 350-362.

35. Hiscock R, Bauld L, Amos A et al. (2012) Socioeconomic status and smoking: a review. Ann N Y Acad Sci $\mathbf{1 2 4 8}$ 107-123.

36. Lanza ST, Collins LM, Lemmon DR et al. (2007) PROC LCA: a SAS procedure for latent class analysis. Struct Equ Modeling 14, 671-694.

37. Muthen B \& Muthen LK (2000) Integrating person-centered and variable-centered analyses: growth mixture modeling with latent trajectory classes. Alcohol Clin Exp Res 24, 882-891.

38. Harrington JM, Dahly DL, Fitzgerald AP et al. (2014) Capturing changes in dietary patterns among older adults: a latent class analysis of an ageing Irish cohort. Public Health Nutr 17, 2674-2686.

39. Keshteli AH, Feizi A, Esmaillzadeh A et al. (2015) Patterns of dietary behaviours identified by latent class analysis are associated with chronic uninvestigated dyspepsia. BrJ Nutr 113, 803-812.

40. Sotres-Alvarez D, Siega-Riz AM, Herring AH et al. (2013) Maternal dietary patterns are associated with risk of neural tube and congenital heart defects. Am J Epidemiol 177, $1279-1288$

41. Torgersen L, Ystrom E, Siega-Riz AM et al. (2015) Maternal eating disorder and infant diet. A latent class analysis based on the Norwegian Mother and Child Cohort Study (MoBa). Appetite 84, 291-298.

42. Vlismas K, Stavrinos V \& Panagiotakos DB (2009) Socioeconomic status, dietary habits and health-related outcomes in various parts of the world: a review. Cent Eur J Public Health 17, 55-63.

43. Kesse-Guyot E, Bertrais S, Peneau S et al. (2009) Dietary patterns and their sociodemographic and behavioural correlates in French middle-aged adults from the SU.VI. MAX cohort. Eur J Clin Nutr $\mathbf{6 3}, 521-528$.

44. Malon A, Deschamps V, Salanave B et al. (2010) Compliance with French nutrition and health program recommendations is strongly associated with socioeconomic characteristics in the general adult population. J Am Diet Assoc 110, 848-856.

45. Bamia C, Orfanos P, Ferrari P et al. (2005) Dietary patterns among older Europeans: the EPIC-Elderly study. Br J Nutr 94, 100-113.

46. Dubuisson C, Lioret S, Touvier M et al. (2010) Trends in food and nutritional intakes of French adults from 1999 to 2007: results from the INCA surveys. Br J Nutr $\mathbf{1 0 3}$, $1035-1048$.
47. Kesse E, Boutron-Ruault MC \& Clavel-Chapelon F (2005) Regional dietary habits of French women born between 1925 and 1950. Eur J Nutr 44, 285-292.

48. Fillol F, Dubuisson C, Lafay L et al. (2011) Accounting for the multidimensional nature of the relationship between adult obesity and socio-economic status: the French second National Individual Survey on Food Consumption (INCA 2) dietary survey (2006-07). Br J Nutr 106, 1602-1608.

49. Cummins S \& Macintyre S (2006) Food environments and obesity - neighbourhood or nation? Int J Epidemiol 35, 100-104.

50. Eisenhauer E (2001) In poor health: supermarket redlining and urban nutrition. GeoJournal 53, 125-133.

51. Wrigley N, Warm D \& Margetts B (2003) Deprivation, diet and food retail access: findings from the Leeds 'food deserts' study. Environ Plan A 35, 151-188.

52. Laraia BA, Siega-Riz AM, Kaufman JS et al. (2004) Proximity of supermarkets is positively associated with diet quality index for pregnancy. Prev Med 39, 869-875.

53. Moore LV, Diez Roux AV, Nettleton JA et al. (2008) Associations of the local food environment with diet quality - a comparison of assessments based on surveys and geographic information systems: the multi-ethnic study of atherosclerosis. Am J Epidemiol 167, 917-924.

54. Estaquio C, Druesne-Pecollo N, Latino-Martel P et al. (2008) Socioeconomic differences in fruit and vegetable consumption among middle-aged French adults: adherence to the 5 A Day recommendation. I Am Diet Assoc 108, 2021-2030.

55. Elstgeest LE, Mishra GD \& Dobson AJ (2012) Transitions in living arrangements are associated with changes in dietary patterns in young women. J Nutr 142, 1561-1567.

56. Macdiarmid J \& Blundell J (1998) Assessing dietary intake: who, what and why of under-reporting. Nutr Res Rev 11, 231-253.

57. Martinez-Gonzalez MA \& Martin-Calvo N (2013) The major European dietary patterns and metabolic syndrome. Rev Endocr Metab Disord 14, 265-271.

58. Pereira S, Katzmarzyk PT, Gomes TN et al. (2015) Profiling physical activity, diet, screen and sleep habits in Portuguese children. Nutrients 7, 4345-4362.

59. Saneei P, Esmaillzadeh A, Keshteli AH et al. (2015) Patterns of dietary habits in relation to obesity in Iranian adults. Eur J Nutr 55, 713-728.

60. Padmadas SS, Dias JG \& Willekens FJ (2006) Disentangling women's responses on complex dietary intake patterns from an Indian cross-sectional survey: a latent class analysis. Public Health Nutr 9, 204-211.

61. Sotres-Alvarez D, Herring AH \& Siega-Riz AM (2010) Latent class analysis is useful to classify pregnant women into dietary patterns. J Nutr 140, 2253-2259.

62. Galobardes B, Morabia A \& Bernstein MS (2001) Diet and socioeconomic position: does the use of different indicators matter? Int J Epidemiol 30, 334-340.

63. Zarnowiecki D, Ball K, Parletta N et al. (2014) Describing socioeconomic gradients in children's diets - does the socioeconomic indicator used matter? Int J Behav Nutr Phys Act 11, 44. 